\title{
Impact of Phytoestrogens on Serum Lipids in Postmenopausal Women
}

\author{
Auswirkungen von Phytoöstrogenen auf die Serumlipide \\ bei postmenopausalen Frauen
}

Authors

Affiliations
M. Terzic ${ }^{1}$, J. Micic ${ }^{2}$, J. Dotlic ${ }^{3}$, S. Maricic ${ }^{4}$, T. Mihailovic ${ }^{5}$, N. Knezevic ${ }^{6}$

The affiliations are listed at the end of the article

Key words
hormone replacement
therapy (HRT)
postmenopausal
phytoestrogens
soy
red clover
serum lipids
Schlüsselwörter
Hormonsubstitution
Phytoöstrogene
Postmenopause
Soja
- Rotklee
- Serumlipide

received 25.3.2012

revised 23.4.2012

accepted 23.4.2012

Bibliography

Dol http://dx.doi.org/

10.1055/s-0031-1298624

Geburtsh Frauenheilk 2012; 72:

527-531 @ Georg Thieme

Verlag KG Stuttgart · New York .

ISSN 0016-5751

\section{Correspondence}

Prof. Milan Terzic, MD, PhD

School of Medicine, University

of Belgrade

Obstetrics and Gynecology

Dr Subotica 8

11000 Belgrade

Serbia

terzicmilan@yahoo.co.uk

\section{Abstract \\ $\nabla$}

Objectives: The aim of the study was to assess the impact of soy- and red clover-derived isoflavones on serum lipid levels in postmenopausal women and to compare the effects to the lipid levels of healthy postmenopausal women without phytoestrogen supplementation.

Materials and Methods: Blood levels of triglycerides, total cholesterol and cholesterol fractions were assessed. Measurements were performed before treatment and at 6 -month intervals over a period of 18 months. The investigation included 74 healthy postmenopausal women randomized into three groups according to treatment. The first group of 23 patients received soy-derived isoflavones, the second group (26 patients) was given red clover-derived phytoestrogens, while the third control group (25 patients) received no supplements.

Results: Mean triglyceride, cholesterol and LDL levels of patients in the control group were significantly higher than in both the soy and the red clover groups $(\mathrm{p}<0.001)$ at all three time points, while mean values did not differ significantly between the soy and the red clover groups. The mean HDL levels of patients in the control group was significantly lower than in both the soy and the red clover groups $(\mathrm{p}<0.001)$.

Conclusions: Phytoestrogen supplementation had a positive metabolic effect on serum lipid levels in postmenopausal women. The impact on serum lipids levels was similar for soy and red clover.

\section{Zusammenfassung \\ $\nabla$}

Ziele: Ziel der Studie war es, den Einfluss von Soja und Rotklee-Isoflavonen auf den Serumlipidspiegel von Frauen nach den Wechseljahren zu beurteilen und die Auswirkungen dieser Isoflavone mit den Blutfettwerten von gesunden postmenopausalen Frauen ohne Phytoöstrogen-Zugabe zu vergleichen.

Materialien und Methoden: Die Blutwerte für Triglyzeride, Gesamtcholesterin und Cholesterinfraktionen wurden gemessen. Blutfettwertmessungen wurden vor der Behandlung und in Abständen von 6 Monaten über einen Zeitraum von 18 Monaten durchgeführt. Es wurden 74 gesunde Frauen nach den Wechseljahren untersucht, die nach dem Zufallsprinzip in 3 Gruppen unterteilt wurden. Die 1. Gruppe von 23 Patientinnen erhielt ein Präparat mit Soja-Isoflavonen, die 2. Gruppe bestand aus 26 Patientinnen, welche Rotklee-Phytoöstrogene erhielten, während die 3. aus 25 Patientinnen bestehende Gruppe als Kontrollgruppe fungierte und keine Isoflavone erhielt. Ergebnisse: Untersuchungen der Blutwerte aller Behandlungsgruppen zeigten, dass Triglyzeride, Cholesterin und LDL-Werte von Patientinnen der Kontrollgruppe signifikant höher waren als in den Soja- und Rotklee-Gruppen ( $p<0,001$ ), während die Mittelwerte zwischen der Soja- und der Rotklee-Gruppe sich nicht signifikant unterschieden. Der HDL-Spiegel von Patientinnen der Kontrollgruppe war signifikant niedriger als der in den Soja- und Rotklee-Gruppen gemessene Wert $(\mathrm{p}<0,001)$.

Schlussfolgerung: Die Zugabe von Phytoöstrogen hat eine positive Auswirkung auf den Serumlipidspiegel von Frauen nach den Wechseljahren. Der Einfluss von Soja und Rotklee auf den Serumlipidspiegel unterscheidet sich nicht wesentlich. 


\section{Introduction}

$\nabla$

Menopause is associated with changes in metabolic profile [1]. Although hormone replacement therapy (HRT) has been shown to have beneficial effects on lipid metabolism, its adverse effects have indicated a need for alternative estrogen-based treatments [2]. This has led to the discovery of a class of estrogenic molecules produced by plants: phytoestrogens which are structurally and functionally similar to $17 \mathrm{~b}$-estradiol. Although phytoestrogens bind to the estrogen receptor at low levels compared with endogenous estrogen, they are still capable of producing estrogenic effects [3]. Soy is a popular food additive because it is free from cholesterol and lactose and rich in vegetable proteins, unsaturated fats, and fiber. It also has abundant amounts of daidzein and genistein, the two most well-known and most potent isoflavones. On the other hand, one of the most extensively studied food supplements has been a phytoestrogen preparation containing red clover-derived isoflavones, as red clover contains the four most important isoflavones [4]. Several investigations have evaluated the effects of isoflavones on serum lipid levels in postmenopausal women, but the results were ambiguous [5-8]. Moreover, there are few comparisons between different phytoestrogen outcomes in literature. Assuming that both soy and red clover contain high amounts of isoflavones, the aim of the present study was to compare the effects of soy and red clover-derived isoflavones on serum lipid levels in postmenopausal women and contrast these effects to lipid levels in healthy postmenopausal women without phytoestrogen supplementation.

\section{Materials and Methods}

$\nabla$

This prospective randomized clinical trial was carried out in the Ultramedica Clinic, American Medical Academy in Belgrade, and in the Clinic of Obstetrics and Gynecology, Clinical Center of Serbia, from September 2008 to June 2010.

Study inclusion criteria were: good general health, no medication that could influence the study results (i.e., anti-osteoporotic, lipid-lowering, anti-hypertensive or hormone-based medication) and postmenopausal status (last menstrual cycle at least 12 months prior to entering the study). Health status was confirmed by a check-up that included detailed anamnesis, examination of gynecological, respiratory and cardiovascular systems (blood pressure, heart rate and ECG), as well as hematological, biochemical, and urine analysis. Women with lipid levels outside the referral range (under, above) and in the referral range were all eligible for the study. Study exclusion criteria were: not fulfilling the inclusion criteria at any time during the study, allergies or severe adverse reactions to the administered drugs, changes to regular dietary habits, interruption of the study protocol, and the patient's wish to withdraw from the study. A clinical sample was constructed. Informed consent was obtained from all women, and the study was approved by the local Research Ethics Committee.

A total of 117 consecutive postmenopausal women who came to us over a period of four months for postmenopausal symptoms (hot flushes, sleep disturbance, mood swings, vaginal dryness) were enlisted into the study. Of these, 74 fulfilled the inclusion criteria and were randomized. Randomization was done by simple manual selection whereby every woman with an odd randomization number received soy supplements while women with an even randomization number received red clover-derived isoflavones. During the study neither the doctors nor the patients knew which group the patient was in or the type of medication administered to the patient.

Women in the control group did not receive any medication and were only used for comparison. Women in this group were randomly selected from a different population consisting of healthy postmenopausal women who had regular colposcopic follow-ups during the same period. Out of a total of 186 such women, 111 fulfilled the inclusion criteria. Simple manual randomization was done whereby every third eligible woman was recruited into the control group of the study.

Thus all women in the study were randomized into one of three groups (soy - S, red clover - RC, control - C) with 37 women in each group. However, 6 women had to be excluded from the soy group and 5 from the red clover group, as they did not take their supplements on a regular basis. Moreover, 7 women from the soy group, 6 from the red clover group and 9 from the control group were excluded because of emerging health problems (hypertension in 11 cases, uterine bleeding in 8 cases and H-SIL in 3 cases). One woman from the soy group wanted to start hormone replacement therapy. Three women decided to drop out from the control group. In the end, 23 women from the soy group, 26 from the red clover group and 25 from the control group completed the study.

A protocol for phytoestrogen administration was compiled by the authors prior to the start of the study. According to this protocol, women were required to take one capsule per day of either soy or red clover-derived phytoestrogens early in the morning before their first meal, continuously over a period of 18 months. The daily soy dose contained 2 isoflavones, genistein $(39 \mathrm{mg})$ and daidzein ( $1 \mathrm{mg}$ ), and the red clover capsule contained 4 isoflavones, biokain A (23 mg), daidzein (1 mg), formononetin (15 mg) and genistein (1 mg). Each patient kept a daily diary listing supplement intake, symptoms and adverse reactions.

We investigated total cholesterol, cholesterol fractions (LDL, HDL) and triglycerides in blood from patients drawn from the cubital vein, and recorded the body height and weight of each subject which were used to calculate the body mass index (BMI) for each patient according to the standard formula. Data were recorded at the beginning of the study and at 6,12 and 18 months after commencing treatment. We compared both randomization arms to a control cohort and to one another. Standard tests for lipid level evaluation were carried out using an Olympus AU 400 automatic analyzer with referral rates for triglycerides (0.61-2.10 mmol/l), total cholesterol (3.63-6.46 mmol/l), HDL (0.75-1.99 mmol/l), and LDL (1.60-4.78 mmol/1).

Data analysis was performed using SPSS version 15 (SPSS, Chicago, IL, USA). Differences between groups were evaluated by descriptive (mean, SD) and analytical statistics. One-sample Kolmogorov Smirnov test (KSZ) and one way ANOVA (Fx, LSD) were used to compare serum lipid levels in patient groups and between group pairs.

\section{Results}

$\nabla$

Both prior to and at all three measurement time points (at 6, 12, and 18 months) the levels of all assessed serum lipids (cholesterol, triglycerides, LDL and HDL) were normally distributed in each $(\mathrm{S}, \mathrm{RC}, \mathrm{C})$ patient group (triglycerides: $\mathrm{S}$ group at 6 months: $\mathrm{KSZ}=0.397, \mathrm{p}_{\max }=0.997$; HDL control at 18 months: $\mathrm{KSZ}=1.261$, $\mathrm{p}_{\min }=0.083$ ). 
Table 1 Patient age and body mass index (mean \pm SD) in investigated and control groups.

\begin{tabular}{|lllllll}
\hline Investigated groups & & $\begin{array}{l}\text { Age at meno- } \\
\text { pause (years) }\end{array}$ & $\begin{array}{l}\text { Patient age } \\
\text { (years) }\end{array}$ & BMI at start & \multicolumn{1}{c}{$\begin{array}{l}\text { BMI at } \\
18 \text { months }\end{array}$} & $\begin{array}{l}\text { No. of } \\
\text { patients }\end{array}$ \\
Phytoestrogen group & Soy & $48.0 \pm 3.6$ & $55.7 \pm 4.0$ & $27.3 \pm 6.6$ & $26.0 \pm 5.2$ & 23 \\
\hline & Red clover & $46.6 \pm 5.1$ & $56.1 \pm 3.9$ & $25.9 \pm 7.0$ & $26.4 \pm 5.8$ & 26 \\
\hline Control group & & $47.7 \pm 4.5$ & $55.2 \pm 5.6$ & $26.7 \pm 5.4$ & $27.5 \pm 4.6$ & 25 \\
\hline
\end{tabular}

Table 2 Average (mean \pm SD) levels of serum lipids in investigated and control groups.

\begin{tabular}{|c|c|c|c|c|c|c|}
\hline & Investigated groups & & Prior to study & At 6 months & At 12 months & At 18 months \\
\hline \multirow[t]{4}{*}{ Cholesterol (mmol/l) } & Phytoestrogen group & Soy & $6.89 \pm 0.47$ & $6.41 \pm 0.41$ & $5.68 \pm 0.36$ & $5.25 \pm 0.41$ \\
\hline & & Red clover & $6.92 \pm 0.47$ & $6.38 \pm 0.44$ & $5.73 \pm 0.43$ & $5.30 \pm 0.42$ \\
\hline & Control group & & $6.87 \pm 0.51$ & $6.95 \pm 0.47$ & $7.04 \pm 0.48$ & $7.13 \pm 0.49$ \\
\hline & p values & & 0.940 & $<0.001$ & $<0.001$ & $<0.001$ \\
\hline \multirow[t]{4}{*}{ Triglycerides (mmol/l) } & Phytoestrogen group & Soy & $3.01 \pm 0.39$ & $2.63 \pm 0.38$ & $2.08 \pm 0.36$ & $1.69 \pm 0.41$ \\
\hline & & Red clover & $3.07 \pm 0.44$ & $2.71 \pm 0.42$ & $2.17 \pm 0.50$ & $1.71 \pm 0.59$ \\
\hline & Control group & & $3.10 \pm 0.39$ & $3.15 \pm 0.40$ & $3.20 \pm 0.41$ & $3.22 \pm 0.39$ \\
\hline & $\mathrm{p}$ values & & 0.743 & $<0.001$ & $<0.001$ & $<0.001$ \\
\hline \multirow[t]{4}{*}{ LDL (mmol/l) } & Phytoestrogen group & Soy & $5.18 \pm 0.23$ & $4.80 \pm 0.23$ & $4.40 \pm 0.26$ & $3.95 \pm 0.30$ \\
\hline & & Red clover & $4.97 \pm 0.23$ & $4.72 \pm 0.25$ & $4.33 \pm 0.27$ & $3.80 \pm 0.31$ \\
\hline & Control group & & $5.20 \pm 0.28$ & $5.29 \pm 0.27$ & $5.36 \pm 0.30$ & $5.39 \pm 0.39$ \\
\hline & p values & & 0.002 & $<0.001$ & $<0.001$ & $<0.001$ \\
\hline \multirow[t]{4}{*}{$\mathrm{HDL}(\mathrm{mmol} / \mathrm{l})$} & Phytoestrogen group & Soy & $0.54 \pm 0.10$ & $0.97 \pm 0.19$ & $1.41 \pm 0.29$ & $1.73 \pm 0.25$ \\
\hline & & Red clover & $0.49 \pm 0.09$ & $0.85 \pm 0.13$ & $1.35 \pm 0.15$ & $1.68 \pm 0.16$ \\
\hline & Control group & & $0.56 \pm 0.09$ & $0.53 \pm 0.08$ & $0.49 \pm 0.05$ & $0.45 \pm 0.10$ \\
\hline & p values & & 0.027 & $<0.001$ & $<0.001$ & $<0.001$ \\
\hline
\end{tabular}

Differences in mean values of evaluated descriptive parameters (age, age at menopause, BMI at the start of the study, BMI at the end of the study) were not significant for any combinations (S-RC, $\mathrm{S}-\mathrm{C}, \mathrm{RC}-\mathrm{C}$ ) of patient groups $\left(\mathrm{t}_{\min }=0.248\right.$ for BMI at 18 months for the $S$ and RC groups; $t_{\max }=1.074$ for age at menopause in the $S$ and RC groups) ( Table $\mathbf{1}$ ).

The average reduction in cholesterol levels was $23.84 \%$ in the $\mathrm{S}$ group and $23.4 \%$ in the RC group compared to an average increase in the control group of $3.84 \%$. The average reduction in triglyceride levels was $43.92 \%$ in the S group and $45.33 \%$ in the RC group, compared to an average increase of $4.1 \%$ in the $C$ group. Average HDL levels were increased by 3.38 times in the $S$ group and by 3.59 times in the RC group while the average decrease in the control group was $15.49 \%$. The average reduction in cholesterol levels was $23.69 \%$ in the $S$ group and $23.33 \%$ in the RC group while the average increase in the control group was $3.99 \%$ (O Table 2).

The differences in cholesterol levels between patient groups were not significant prior to treatment $(\mathrm{p}=0.062)$ but were highly significant $(\mathrm{p}<0.001)$ at all three measurement time points $(6$ months: $\mathrm{Fx}_{6}=13.897 ; 12$ months: $\mathrm{Fx}_{12}=86.770 ; 18$ months: $\mathrm{Fx}_{18}=155.379$; $\bigcirc$ Table 2). At all three measurement time points the mean cholesterol level of patients in the control group was significantly higher than those of both the soy and red clover groups ( $p<0.001$ ), while mean cholesterol values did not differ significantly between soy and red clover groups ( Table 3 ).

Differences in triglyceride levels between patient groups were not significant $(p=0.743)$ before starting treatment but were highly significant $(\mathrm{p}<0.001)$ at all three measurement time points during treatment $\left(\mathrm{Fx}_{6}=12.838 ; \mathrm{Fx}_{12}=54.094 ; \mathrm{Fx}_{18}=\right.$ 90.110; - Table 2). At all three measurement time points the mean triglyceride level of patients in the control group was significantly higher than in both the $S$ and RC groups $(\mathrm{p}<0.001)$,
Table 3 Statistically significant differences in serum lipid levels in investigated group pairs.

\begin{tabular}{|c|c|c|c|c|}
\hline $\begin{array}{l}\text { Serum } \\
\text { lipids }\end{array}$ & Time point & Groups & $\begin{array}{l}\text { Mean } \\
\text { difference }\end{array}$ & p value \\
\hline \multirow[t]{6}{*}{ Cholesterol } & 6 months & C-S & 0.538 & $<0.001$ \\
\hline & & C-RC & 0.572 & $<0.001$ \\
\hline & 12 months & C-S & 1.358 & $<0.001$ \\
\hline & & C-RC & 1.310 & $<0.001$ \\
\hline & 18 months & C-S & 1.880 & $<0.001$ \\
\hline & & C-RC & 1.828 & $<0.001$ \\
\hline \multirow[t]{6}{*}{ Triglycerides } & 6 months & C-S & 0.520 & $<0.001$ \\
\hline & & C-RC & 0.447 & $<0.001$ \\
\hline & 12 months & C-S & 1.114 & $<0.001$ \\
\hline & & C-RC & 1.031 & $<0.001$ \\
\hline & 18 months & C-S & 1.527 & $<0.001$ \\
\hline & & C-RC & 1.512 & $<0.001$ \\
\hline \multirow[t]{6}{*}{ LDL } & 6 months & C-S & 0.493 & $<0.001$ \\
\hline & & C-RC & 0.579 & $<0.001$ \\
\hline & 12 months & C-S & 0.957 & $<0.001$ \\
\hline & & C-RC & 1.028 & $<0.001$ \\
\hline & 18 months & C-S & 1.442 & $<0.001$ \\
\hline & & C-RC & 1.589 & $<0.001$ \\
\hline \multirow[t]{7}{*}{$\mathrm{HDL}$} & 6 months & C-S & -0.443 & $<0.001$ \\
\hline & & C-RC & -0.329 & $<0.001$ \\
\hline & & S-RC & -0.114 & 0.008 \\
\hline & 12 months & C-S & -0.919 & $<0.001$ \\
\hline & & C-RC & -0.860 & $<0.001$ \\
\hline & 18 months & C-S & -1.275 & $<0.001$ \\
\hline & & C-RC & -1.231 & $<0.001$ \\
\hline
\end{tabular}

C: control, S: soy, RC: red clover 
while there was no significant difference in mean values between the $S$ and the RC group ( 0 Table 3 ).

The difference between LDL levels in patient groups at the start of the study and at all three time points was highly significant $\left(\mathrm{p}<0.001 ; \quad \mathrm{Fx}_{0}=7.041 ; \quad \mathrm{Fx}_{6}=39.271 ; \quad \mathrm{Fx}_{12}=97.513 ; \quad \mathrm{Fx}_{18}=\right.$ 157.239; O Table 2). At the beginning of the study the mean LDL levels of women in the control group were not significantly different from those in the soy group ( $p=0.780)$ but highly significantly higher than those of the women in the RC group $(p=0.001)$. The mean LDL level was significantly higher in the $S$ group compared to the RC group $(p=0.003)$. At all three time points during the study the mean LDL level of patients in the control group was significantly higher than in both the soy and the red clover group $(p<0.001)$, while the mean values in the soy and red clover groups did not significantly differ from each other (OTable 3).

The differences in HDL levels between patient groups were significant $(\mathrm{p}=0.027)$ before starting treatment and were highly significant at all three time points $\left(\mathrm{Fx}_{6}=61.267 ; \mathrm{Fx}_{12}=156.476 ; \mathrm{Fx}_{18}=\right.$ 359.167; O Table 2). Before treatment, the mean HDL levels of women in the control and the soy groups and in the soy and the red clover groups did not differ significantly, while the mean HDL level in the control group was highly significantly higher than in the RC group $(\mathrm{p}=0.001)$. At all three measurement time points the mean HDL level of patients in the control group was significantly lower than in both the soy and the red clover groups $(p<0.001)$. The mean HDL level in the soy group was only highly significantly higher than in the red clover group after 6 months of treatment ( $\bigcirc$ Table 3 ).

\section{Discussion}

$\nabla$

We found that phytoestrogens derived from both soy and red clover have a positive metabolic effect on serum lipids of postmenopausal women. Both soy and red clover supplement were found to have an almost equal impact on serum lipid levels.

In postmenopausal women, total cholesterol, LDL cholesterol and triglyceride levels are increased and HDL cholesterol is decreased compared with premenopausal women of the same age and BMI $[1,9]$. Hormone replacement therapy has known to lower total and LDL cholesterol and to slightly increase HDL cholesterol, thus lowering the risk of cardiovascular disease in the postmenopausal period. But since HRT therapy can have numerous adverse effects and consequences and, most importantly, carries a higher risk of breast cancer and endometrial malignancy, phytoestrogens were introduced into clinical practice [10-12].

The efficacy of these substances can be explained by their specific binding to the estrogen receptor. There are two types of estrogen receptors (ER): ER $\alpha$ and ER $\beta[3,13]$. Phytoestrogens bind weakly to $E R \alpha$ receptors and more strongly to ER $\beta$ receptors and possess organ-specific estrogenic and antiestrogenic effects, acting as partial agonists in some tissues and as antagonists in others. ER $\beta$ receptors are located in vascular walls and bone cells, while ER $\alpha$ receptors are found in the endometrium and breast tissue. Therefore, women receiving phytoestrogen medication experience two benefits: (1) an increase of HDL cholesterol and (2) a down-regulation of ER $\alpha$ receptor caused by phytoestrogens binding to ER $\beta$ receptors $[13,14]$.

Phytoestrogens can be derived from numerous plants but are predominantly obtained from soy and red clover. Both plants are safe and nontoxic, and also contain other beneficial substances, such as polifenoles, which are potent antioxidants [2]. Recent studies have confirmed that phytoestrogens have a favorable impact on serum lipid levels [15-18].

Red clover is considered to have an advantage compared to other plants containing phytoestrogens as red clover is the only plant from which four of the most important isoflavones (biokain $\mathrm{A}$, daidzein, formononetin and genistein) can be derived [19]. Soy contains only two isoflavones, but they are particularly potent: daidzein and genistein. Moreover, some studies have shown that the displayed benefits attributable to isoflavones are mainly due to the effects of daidzein and genistein $[19,20]$. The results of our study also appear to support this viewpoint as the impact of therapy using soy supplements that contained daidzein and genistein were similar to the effects achieved by the administration of all 4 isoflavones in the red clover supplement. On the other hand, other isoflavones in red clover also might have an impact on serum lipid levels, as red clover has low levels of genistein. Some authors have pointed out that different isoflavones have different mechanisms of action and, therefore, a different influence on serum lipid levels [5]. Additional studies like ours comparing the sources of different types of isoflavones should be undertaken in order to fully understand the relevance of specific isoflavone types.

Mean cholesterol and triglyceride levels before commencing therapy were lower in the control group, but after only 6 months of treatment these levels were significantly higher than in patients from both the soy and the red clover groups. Supplementation with soy and red clover had similar effects on cholesterol and triglyceride serum levels. Mean LDL level in the control group before treatment was insignificantly higher than in the soy group and significantly higher than in the red clover group. After 6 months of treatment the mean LDL level in the control group was highly significantly higher compared to both groups of women who received phytoestrogens. The mean HDL level in the control group at the beginning of the study was somewhat higher than in the soy group and significantly higher than in the red clover group. Just 6 months after starting therapy, the mean HDL level in the control group was significantly lower than in either the soy or the red clover groups. Supplementation with soy or red clover had similar effects on LDL and HDL levels. All of the results with regard to the effects on total cholesterol and LDL levels obtained in our study are consistent with most of the data in the literature [15-18]. As for HDL levels, the results of some studies support our findings $[5,15,17,18]$, while other studies could not confirm our data $[8,16]$. The extent of the impact of red clover and soya-derived phytoestrogens on HDL levels in other investigations was similar to that in our study (3-4\%). The decrease in HDL levels in the control group (15.5\%) could be explained by their continuing their established nutritional patterns throughout the 18-month period.

According to current advice, dietary supplements should contain at least $40 \mathrm{mg}$ of isoflavones per day $[21,22]$. Although our patients received pills with different concentrations of specific isoflavones, their overall effect on serum lipid levels did not differ. This might be due to the fact that both pills consisted of the same overall amount of phytoestrogens $(40 \mathrm{mg})$, as advised. But whether changes in dosages of specific isoflavones will result in diverse outcomes should be investigated in further studies. All patients investigated in our study were similar with regard to factors that could have an influence on the therapy, i.e., BMI at the beginning and at the end of the study, age, and age at menopause. Further studies could investigate whether differences in age and 
BMI and appropriate adjustments for age and BMI could affect results.

Numerous studies have shown that isoflavone supplementation, taken over a period of a couple of months, is safe, with no sideeffects [12]. Because no side-effects were detected in our study which had a follow-up period of 18 months, it can be concluded that isoflavone supplementation may be safe to use for even longer periods. Moreover, according to the results of our study, to achieve a positive impact on serum lipids, phytoestrogen supplementation should be administered for at least 6 months. Patients from both investigated groups were highly motivated to take the medication and therefore the dropout rate was generally low. One of the reasons for this motivation could be that high serum lipid levels were found in the majority of patients at the beginning of the study.

There are almost no studies in the literature that have investigated the possible differential effects of supplementation by red clover or soy. Therefore, our findings offer new insights for the introduction of phytoestrogen supplementation in postmenopausal women. We have shown that there is no difference in the metabolic effects of soy and red clover-derived isoflavones on serum lipid levels, so both sources of phytoestrogens can be used equally.

Finally, our study had its limitations. The clinical sample was relatively small. However, the study groups were comparable to those of other studies in the field of postmenopausal therapies. Moreover, the arbitrary order of the patients' visits and the randomized patient distribution to the investigated groups provided a patient selection which was free of bias. Another problem with our study was that it was not designed as a completely doubleblinded investigation, but we will leave that for future trials. We wished to avoid a placebo effect in the control group and, therefore, patients in the control group were not given any form of medication. A placebo-controlled study might be undertaken in further investigations. The fact that the control cohort was not part of the randomization population could be considered as the biggest drawback of this study. However, we considered it proper to treat (either with soy or red clover phytoestrogens) all women who came to us complaining of menopausal symptoms (the randomization population). Furthermore, we wanted to have a control group that did not have any menopause-related health problems. All three groups fulfilled the same inclusion criteria and were randomized, which diminishes selection bias.

\section{Conclusions}

In this study, phytoestrogen supplementation derived either from soy or red clover was found to have a favorable metabolic impact on serum lipids in postmenopausal women. Both soy and red clover supplements showed an almost equal impact on serum lipid levels. Phytoestrogen supplementation had no sideeffects, so this approach could be considered safe. All patients were satisfied with the result of the administered medications.

\section{Conflict of Interest}

$\nabla$

None.

\section{Affiliations}

${ }^{1}$ Obstetrics and Gynecology, School of Medicine, University of Belgrade, Belgrade, Serbia

2 Clinical Center of Serbia, Institute of Obstetrics and Gynecology, School of Medicine, University of Belgrade, Belgrade, Serbia

${ }^{3}$ Clinical Center of Serbia, Institute of Obstetrics and Gynecology, Belgrade, Serbia

${ }^{4}$ General Health Center "Savski Venac", Belgrade, Serbia

${ }^{5}$ Ultramedica Clinic, American Medical Academy, Belgrade, Serbia

${ }^{6}$ Department of Anesthesiology, University of Illinois; Department of

Anesthesiology, Advocate Illinois Masonic Medical Center, Chicago, United States

\section{References}

1 Polotsky HN, Polotsky AJ. Metabolic implications of menopause. Semin Reprod Med 2010; 28: 426-434

2 Brockie J. An alternative approach to the menopause. Obstet Gynaecol (Lond) 2006; 8: 96-102

3 Ascenzi P, Bocedi A, Marino M. Structure-function relationship of estrogen receptor alpha and beta: impact on human health. Mol Aspects Med 2006; 27: 299-402

4 Panay $N$. Taking an integrated approach: managing women with phytoestrogens. Climacteric 2011; 14: 2S-7S

5 Geller SE, Studee L. Soy and red clover for midlife and aging. Climacteric 2006; 9: 245-263

6 Birkhauser MH, Panay N, Archer DF et al. Update practical recommendations for hormone replacement therapy in the peri- and postmenopause. Climacteric 2008; 11: 108-123

7 Thorp AA, Howe PR, Mori TA et al. Soy food consumption does not lower LDL cholesterol in either equol or nonequol producers. Am J Clin Nutr 2008; 88: 298-304

8 Wong JM, Kendall CW, Marchie A et al. Equol status and blood lipid profile in hyperlipidemia after consumption of diets containing soy foods. Am J Clin Nutr 2012; 95: 564-571

9 Roush K. Menopausal hormone therapy: what we know now. Am J Nurs 2011; 111: 38-47

10 Taylor HS, Manson JE. Update in hormone therapy use in menopause. J Clin Endocrinol Metab 2011; 96: 255-264

11 Jaakkola S, Lyytinen HK, Dyba T et al. Endometrial cancer associated with various forms of postmenopausal hormone therapy: a case control study. Int J Cancer 2011; 128: 1644-1651

12 Powles TJ, Howell A, Evans DG et al. Red clover isoflavones are safe and well tolerated in women with a family history of breast cancer. Menopause Int 2008; 14: 6-12

13 McCarty MF. Isoflavones made simple - genistein's agonist activity for the beta-type estrogen receptor mediates their health benefits. Med Hypotheses 2006; 66: 1093-1114

14 Jefferson A. Dietary phytoestrogens - a role in women's health. Nutr Food Sci 2003; 33: 16-22

15 Terzic M, Dotlic J, Maricic S et al. Influence of red clover-derived isoflavones on serum lipid profile in postmenopausal women. J Obstet Gynecol Res 2009; 35: 1091-1095

16 Taku K, Umegaki K, Sato Y et al. Soy isoflavones lower serum total and LDL cholesterol in humans: a meta-analysis of 11 randomized controlled trials. Am J Clin Nutr 2007; 85: 1148-1156

17 Zhan S, Ho SC. Meta-analysis of the effects of soy protein containing isoflavones on the lipid profile. Am J Clin Nutr 2005; 81: 397-408

18 Potter SM, Baum JA, Teng $\mathrm{H}$ et al. Soy protein and isoflavones: their effects on blood lipids and bone density in postmenopausal women. Am J Clin Nutr 1998; 68: 1375S-1379S

19 Beck V, Rohr U, Jungbauer A. Phytoestrogens derived from red clover: An alternative to estrogen replacement therapy? J Steroid Biochem Mol Biol 2005; 94: 499-518

20 Lorand T, Vigh E, Garai J. Hormonal action of plant derived and anthropogenic nonsteroidal estrogenic compounds: phytoestrogens and xenoestrogens. Curr Med Chem 2010; 17: 3542-3574

21 Clarke DB, Bailey V, Lloyd AS. Determination of phytoestrogens in dietary supplements by LC-MS/MS. Food Addit Contam 2008; 25: 534547

22 Terzic M, Micic J, Dotlic J. Phytoestrogen Use in menopausal Patients: current clinical Approach. In: Fiala J, Pospíšil D, eds. Alfalfa and Clovers: Properties, medicinal Uses and Health Benefits. New York, NY, USA: Nova Science Publishers, Inc; 2011: 55-62 